\title{
On Asymmetric Business Cycles and the Effectiveness of Counter-Cyclical Fiscal Policies
}

\author{
Nicolas E. Magud ${ }^{*}$ \\ University of Oregon
}

This draft: May 2005

First draft: December 2002

\begin{abstract}
In the presence of informational frictions and uncertainty, an investment model is developed to capture the asymmetric dynamics of business cycles. When affected by a negative shock, the economy responds differently than when hit by a positive shock, both in terms of size and recovery length. In this set up, the role for fiscal policy in smoothing the effects of business cycles fluctuations depends on the initial conditions of the economy at the time of the shock: based on the degree of fiscal fragility of the government, expansionary fiscal policy might be expansionary or contractionary in terms of output.
\end{abstract}

Keywords: Asymmetric Information, Business Cycles, Fiscal Fragility, Fiscal Policy.

JEL Classification: H32, E00, E22.

\footnotetext{
${ }^{*}$ Department of Economics, University of Oregon, Eugene, 1285 University of Oregon 97403, USA. Email: magud@uoregon.edu. I thank Roger Betancourt, Fernando Broner, Federico Guerrero, John Haltiwanger, Daniel Heymann, Mike Pries, Daniel Ortega, Carmen Reinhart, Pedro Rodriguez, John Shea, Juan Trevino, Esteban Vesperoni, and seminar participants at University of Maryland for insightful comments, suggestions and stimulating conversations out of which this product emerged. All remaining errors are mine.
} 


\section{Introduction}

Countries are, for one reason or another, continuously experiencing some degree of cyclical fluctuations in output. Economic theory has ceaselessly looked for explanations of these facts happening along with the optimal policy response to each possible configuration in order to provide the policy maker with a complete toolkit for solving the short run as well as the long run contingencies he/she might encounter. However, depending on the academic school in which the analyst is inspired, policy reactions to the same type of events sharply disagree.

For example, lets consider two polar cases. When dealing with a sustained recession, the standard Keynesian policy recipe is to expand aggregate demand by intervening in the market through increases in government expenditures. The economy will experience a direct increase in aggregate demand that, through the multiplier -textbook- process will boost the economy out of a recession. The budget deficit that will be consequently increased should not be a major warning provided intertemporal solvency is fulfilled.

If the same problem is posed to what we can call in a broad sense a classical -orthodox- economist then, contrary to the previously sketched policy response, the best for the policy maker to do is to reduce government expenditure because this will reduce governments budget deficit. In turn, this will reduce demand for credit, decrease the interest rate and consequently increase demand for investment; therefore the economy steps out of the recession via private sectors actions.

Then, what should the policy maker do? By looking at the stated explanations, both seem to make sense. Consequently the dilemma is which policy reaction function should an optimizing decision-maker put into practice.

With these ideas in mind, the objective of these lines is twofold. On the one hand, I will show that actually both explanations are correct. Which of them to choose will basically depend on the economys initial conditions. On the other hand, I will firstly analyze what could be the sources of these fluctuations. In a sense, the former question deals with a positive aspect of business cycles, while the latter focus on the normative issue that it generates.

The standard plot of any output time series shows an asymmetric diagram ${ }^{1}$ as the data shows. The empirical evidence supports the claim of asymmetric business cycles, as documented in the work by Acemoglu and Scott (1997) and Beaudry and Koop (1993) ${ }^{2}$ among others and already posed by Keynes (1936) in that periods of negative growth rates - recessions - last much less than periods of recovery.

It is worth noting though, that the asymmetry in the business cycle can be understood in two different ways. One is how long does the economy take to return to its trend after being hit by a shock, namely the propagation effect. Another issue is related to the amplification a shock can have. The latter focus on the impact that the same shock causes on the economy depending on it being positive or negative. To put it simply, if affected by a negative shock, will the economy

\footnotetext{
${ }^{1}$ Defined for the moment as sharp contractions and slow recoveries.

${ }^{2}$ Also Sichel (1989), Sichel (1993), Nefcti (1984), Stock and Watson (1999), Burns and Mitchel (1946) and Mitchel (1927), Chalkley and Lee (1998) and Veldkamp (2001).
} 
respond with the same negative fall in output as the raise it will experience should the shock be positive? The tentative answer is no, and the model below will try to capture both characteristic of asymmetry regarding the business cycle.

Now, what makes investment -the main source of output variability- to be asymmetric? Consider the following argument. Information is not only asymmetric, but also incomplete. ${ }^{3}$ Given this, investors are more reluctant to invest after the economy falls into a recession because of the difficulty in assessing the length and duration of it. Then, it is sometimes better to wait for more information before making irreversible decisions. As a consequence, times of low economic activity that should otherwise last for short periods may become longer than expected. The overall effect will be the economy remaining in the trough for longer than necessary, with the generally known welfare reduction so implied.

In all this argument credit markets play a key role. If firms are restrained from credit, economic recovery will be negatively affected. Moreover, if the recession turns out to be longer or deeper than expected then prices are likely to eventually decrease, reducing the value of indebted firms means of repayment while increasing their real debt burden. Consequently more bankruptcies might arise at the same time credit becomes more stringent. This credit channel line of argument extends the literature developed by Bernanke and Gertler (1989), Bernanke and Gertler (1993), Bernanke and Gertler (1995), Kiyotaki and Moore (1997), Bernanke, Gertler and Gilchrist (1999) regarding the role played by credit markets in amplifying and propagating shocks.

Given all this, what is the role played by fiscal policy in getting the economy out of the recession? It will be shown that policy responses will vary according to initial conditions. Increasing government expenditures implies that either taxes or debt will be increased -or both- generating an incentive to reduce private investments.

However, this will be true only for developing economies ${ }^{4}$ since industrialized economies can usually obtain all the liquidity they need to generate a sharp increase in aggregate demand through government purchases -which can lead the economy out of the recession in a standard Keynesiantype mechanism. This is due to some sort of credibility regarding the repayment ability of developed countries.

On the contrary, developing countries credibility is usually lower, which is reflected in the higher risk premiums they pay. It will be shown that this analysis can be summarized in one variable: initial degree of indebtedness relative to sustainable GDP. If countries show low levels of debt when a recession strikes, the amount of public expenditure a government can finance by issuing more debt is large enough so as to display a standard Keynesian counter-cyclical policy.

But if countries are highly indebted, then the increase in debt they are permitted in order not to break ex ante intertemporal solvency is relatively small. Then, they are not able to credibly finance large increases in government expenditures. Consequently, if they engage in these policies the former contractionary effect of fiscal policy will dominate the latter expansionary effect.

\footnotetext{
${ }^{3}$ Informational cycles have been studied by Zeira (1987) and Zeira (1999) among others.

${ }^{4}$ Broadly defined for the moment.
} 
Evidence on the effectiveness of counter-cyclical polices can be easily found in the literature. Some papers deal with the expansionary effects of fiscal contractions for OECD countries, such as Alesina and Perotti (1997), Giavazzi and Pagano (1990), Giavazzi and Pagano (1996), Hallet, Strauch and Von Hagen (2001) and Alesina and Ardagna (1998). Alesina, Pratti, and Tabellini (1990) and Alesina, De Broeck, Pratti and Tabellini (1992) deal with indebtedness levels and multiple equilibria. Alesina, Ardagna, Perotti and Schiantarelli (1998) study the impact of fiscal contractions on investment. Baldacci, Cangiano, Mahfouz and Schimmelpfennig (2001) and Perotti (2000) document the different responses to counter-cyclical fiscal polices controlling for initial conditions. Blanchard and Perotti (2000), Edelberg, Eichenbaum and Fisher (1998) and Burnside, Eichenbaum and Fisher (2001), focus on expansionary polices in the U.S. Talvi and Vegh (2000) study the procyclicality of fiscal policies for OECD and developing countries. At the theoretical level, the existent literature on fiscal consolidation -although not necessarily to account for countercyclical policy and recurring to different arguments and set ups in each case- include Blanchard (1984), Blanchard (1990), Drazen (1990), Bertola and Drazen (1993), Sutherland (1997) and Miller, Skidelski and Weller (1990). ${ }^{5}$

The rest of the paper is organized as follows. In section (2)we set up the basic model economy, in which asymmetric business cycles due to informational characteristics arise as a consequence of the informational structure and the decision-making mechanism of private investors. In section (3) the model is extended by adding the government and the implications of the counter-cyclical policies are studied. Finally, section (4) concludes.

\section{Model Economy}

\subsection{Overview and Conceptual Framework}

Individuals receive incomplete and private information and try to infer others information in order to make investment decisions. Since individuals cannot observe others information they will have to learn as much as possible from their actions (which will obviously be a space with smaller measure than the information one). Moreover, we will observe that this learning process evolves endogenously, being one of the causes for recoveries to take longer.

This literature is part of what is usually known as social learning, which include papers by Gale (1996a), Gale (1996b), Chamley and Gale (1994) and Chamley (1997) to explain the decisionmaking process in the context of asymmetric information. It has also been used by Caplin and Leahy (1993) and Caplin and Leahy (1994) to explain economic fluctuations, crises and the welfare reductions generated by the lack of symmetric information. One difference, though, is that these type of models work with sequential decision-making as if agents were in a line that orders the timing of their choices. On the contrary, although each agent has a sequence of investment decisions of that kind, in this model agents simultaneously make their investment decisions observing others actions;

\footnotetext{
${ }^{5}$ Drazen (2000) surveys on issues of fiscal policies, debts and budget deficits as well as fiscal consolidations.
} 
graphically, this will be like a continuum of parallel lines instead of just one line.

Intuition of the model: suppose the economy starts in a recession and that investment decisions have to be made. Also, assume that entrepreneurs are risk neutral individuals who are faced with investment opportunities but they are forced to borrow in order to invest. For them to decide whether to invest or not, they have to consider the expected returns net of repaying their debt. In this decision it is also included the opportunity cost of waiting. For some degree of uncertainty about the pros and cons of investing, they would rather wait for more information in order to make the decision. Consequently, the value that firms attach to information is observed through the value of delay. It might be the case that, even discounting for the forgone income due to not investing, delaying investing is the optimal strategy of firms operating in a world of incomplete information. ${ }^{6}$ 7 The direct implication is that due to this amplification mechanism generated by informational failures recessions could last longer than what they should -absent the informational problem.

Specifically, firms will decide whether to ask for the loan to finance their investment today and earn profits from today onwards, or to wait for one period to collect more information and then choose whether to invest or not. If for any firm the state of nature is good in expected terms, it will not delay investment; otherwise, it would rather wait and see before comprising into debt.

However, note that this does not necessarily displays asymmetric business cycles as observed in the data. There is something else: individuals reactions are per se asymmetric. Intuitively, it is not the same for a firm that was expecting a good performance for the economy to occur to find out that is even better that expected, than to suddenly realize that irreversible investment decisions were made expecting a -rationally-promising future and the state of nature turned out to be less productive than expected. This is what Bernanke (1983) called the bad news principle. Finding out things are better that expected doesnt give any extra information and consequently no decisions would be changed. However, finding out things are worse than optimally expected may give rise to individuals preferring changing their decisions had they knew it in advance. In an irreversible investment environment, this generates a value for delay that cannot be disregarded as of second order.

And this is an asymmetric process: if a firm realizes that the state of nature is worst than expected, it will incur in no further project due to its lack of expected success. On the contrary, firms have to be relative confident in order to prefer investing today instead of waiting. Otherwise, they will better wait for more information before making an irreversible investing decision even if the true state of demand is good! This is the effect of the existence of the mentioned bad news principle, in which only bad news matter for investment decisions.

For a risk neutral lending sector and given uncertainty, the best strategy financial intermediaries can put into practice is to lend according to what firms are able, in expected terms, to repay, i.e. the expected proceeds of their sales. On this basis, financial intermediaries will recover their capital plus the stipulated interest if the state of nature turns out to be as expected. However, once investment

\footnotetext{
${ }^{6}$ Dixit and Pindyck (1994).

${ }^{7}$ Note that part of firms information comes from other firms actions, i.e. their very own decisions to invest.
} 
is made and the state of nature is publicly revealed, if it occurs to be worst than expected, some firms may become ex post insolvent (this argument has already been stated by Fisher (1933) in his debt deflation theory). Firms will go bankrupt and given the non-existence of physical collateral they will be able to pay at most their realized sales at market obtained prices.

In a dynamic setting, bankruptcy will have a sort of intertemporal multiplier effect. This works as follows: for those firms that have to decide tomorrow whether to invest or not based on private information and public actions, observing that today there are more bankruptcies than expected plays the role of biasing the information towards higher probabilities of the state of nature being bad. Consequently, it is more likely for this to create a higher tendency for firms to prefer delay instead of investing, thus causing the recession to be longer than already expected.

Then we introduce a simple government structure that finances its stream of expenditures solely by collecting income taxes and issuing debt. In this set up, in case of a recession, the usually observed effect that tax collection will be reduced is straightforward. Suppose an ex ante intertemporally solvent government that experiences a longer or deeper than expected recession. Note that unless the government reduces its expenditures so as to intertemporally re-balance its budget, no debt roll over is likely to appear in the near future (the higher the debt level, the sooner this will happen!). Observe that this is the consequence of the following mechanism: the lower tax revenue is, the more debt-dependable the government becomes if no adjustment is put in place. As a consequence, the deeper the recession, the higher is the speed at which national debt increases. Given a solvency restriction, the maximum amount of debt a government can issue is reached earlier. Consequently, the governments ability to repay its debt can be naturally put into question. If the country is perceived as insolvent, then no market player would like to have this countrys debt in its portfolio, prices of sovereign bonds will decrease and the country risk will sharply rise, making the situation even worse -sort of a vicious circle. This might make investment decrease further, and then more firms may become bankrupt, decreasing tax revenue even further.

On the other hand, and provided that it is financially feasible, the government, realizing of the situation -longer or deeper than expected recession- can work as a coordination device by increasing public expenditures and so providing for higher expectations for good state of nature to occur through increases in aggregate demand. By so doing, the government is able to solve -at least partially- the coordination failure that this economy is displaying. This is done by a government that works as a coordinating device between market failures and true state of demand through the information channel.

Therefore, this mechanism will work in making the economy to survive to the recession faster depending on initial condition. ${ }^{8}$ For a highly indebted government, this type of policy will not work, whereas for a relatively low indebted country it will. For a country that starts with a lower debt level is ex ante more likely to continue being intertemporally solvent. Instead, a highly indebted country is ex ante more likely to default on its debt. In a sense, applying standard Keynesian counter-cyclical polices are only effective for credible or ex ante intertemporally solvent countries

\footnotetext{
${ }^{8}$ It will be observed that, unlike Diamond (1981), the optimal policy response is an endogenous one.
} 
but not for others.

\subsection{Formal Analysis}

Suppose there is a continuum of agents in the unit interval. Aggregate demands state of nature, $s_{t}$, follows a Markov process and can take on only two values, which will be labelled as good and bad, according to the following structure:

$$
s_{t+1}=\left\{\begin{array}{l}
G: R_{t+1}=(1+u) R_{t} \\
B: R_{t+1}=(1-d) R_{t}
\end{array}\right.
$$

where $0<u<1$ and $0<d<1$.

This implies that demand in period $t+1, R_{t+1}$, will increase in the good state of nature and decrease in the bad state. Assume that the state of natures stochastic process is given by a symmetric Markov chain, according to which the probabilities of each state of nature occurring, conditional on previous periods state of nature, are given by:

$$
\begin{gathered}
\operatorname{Pr}\left[s_{t+1}=B \mid s_{t}=B\right]=\operatorname{Pr}\left[s_{t+1}=G \mid s_{t}=G\right]=p \\
\operatorname{Pr}\left[s_{t+1}=B \mid s_{t}=G\right]=\operatorname{Pr}\left[s_{t+1}=G \mid s_{t}=B\right]=(1-p)
\end{gathered}
$$

where $p \in(0,1)$. Each generation (or cohort) of individual investors live for three periods: $t$, $t+1$ and $t+2 .{ }^{9}$ They are risk neutral. As can be seen in Figure (??), in period $t$ they face the opportunity to either invest in that period or wait for more information and decide whether to invest or not in period $t+1$. In case they choose to invest today, they will receive the proceeds - actually the sales - from this investment project only in periods $t$ and $t+1$. This raises the incentives for investors to try to invest as soon as possible in order not to pay the opportunity cost of waiting, which is reflected in the income forgone during period $t$, especially in case demand goes down in period $t+1$. In this sense, if any entrepreneur decides to wait for more information before making the investment decision he will only be able to receive some income from selling the goods during period $t+1$. Note also that if the entrepreneur does not invest in period $t+1$ then he will also be not taking advantage of the investment opportunity he faced. ${ }^{10}$

However, given the uncertainty of the environment, there is a benefit that can be derived from waiting. If the investor is too uncertain about the true state of demand - in a sense, he is attaching a high probability to the state of nature being bad - he would rather wait one period in order to collect more information before making a decision. This wait and see policy reaction of the private entrepreneur is a direct consequence of investment being irreversible. Given that once that

\footnotetext{
${ }^{9}$ Once each generation gets out the market their sons occupy the space they were already using, and inherit their investment opportunities, so it is like investors - firms - would live forever.

${ }^{10}$ We can think of the investment opportunity as a right to exploit a patent that lasts two periods.
} 
capital is installed it can no longer serve another purpose, investors should have to attach a high probability to a good state of nature in order for investing today being optimal, because otherwise they will prefer either to wait for more information or not to invest at all. The latter will happen in case investors attach low probabilities to the economy being in the good state of nature and once in period $t+1$ they realize they were correct, leading them not to invest at all.

This can be summarized in that individual agents can, given their available information - to be defined below - decide to take one of the following actions, $a_{t}$, in each period $t$ :

$$
a_{t}= \begin{cases}1 & \text { invest } \\ 0 & \text { do not invest }\end{cases}
$$

$\forall t$. Given that individuals are risk neutral, the decision of whether $a_{s}$ will be 0 or 1 will be based on looking at the net present value (NPV) of investment. However, since agents face the opportunity to invest but do not have the capital to actually do it, they are forced to go into the capital markets in order to raise the necessary funds to finance their projects; i.e. they have to ask for loans. We have to consider this before computing the NPV of investing because repayment should be taken into account when computing it. In this regard, we will assume that individuals ask for loans only when they decide to invest and are given the funds instantaneously. The debt contract specifies that repayment (capital plus interests) is due the following period. Figure (??) represents the time line for a "generations opportunities and possible outcomes. ${ }^{11}$

\section{INSERT FIGURE I HERE}

Then, if an entrepreneur decides to invest during period $t$ he will produce during that period and the following one, repaying his debt during the latter. Note we are assuming that each entrepreneur lives (at least in terms of a project) for three periods, being able to produce only when young, i.e., during the first two periods of life but not during his last one. On the contrary, if he chooses to wait and invests in period $t+1$ he will produce during $t+1$ and repay during $t+2$, but he will not be able to produce during the last period. Implicitly, we are assuming that new investment opportunities are received by entrepreneurs but only after they have repaid their debt (which is the same as saying that loans will only be issued in favor of those individuals that have shown their repayment willingness). Therefore, investors have incentives not to delay investment because of the opportunity cost they experience as a consequence of not producing - i.e. reducing their production temporal length - which are obviously to be compared with the incentives to delay in order to collect more information and decide on that basis. We also assume that the total amount of individuals with investment opportunities remains constant. Given free entry, whenever an entrepreneur defaults he gets out of the market and another one enters to replace it.

The role of lenders can be put as follows. They want to earn a profit out of the loans they give but they don't know whether firms are going to be able to repay their debts. The former being risk neutral, they will approve investment loans according to the expected present value, provided that

\footnotetext{
${ }^{11}$ Recall that at each period a new generation has decisions to be made.
} 
in the event of a worse than expected outcome of aggregate demand they will at least be able to collect the proceeds from sales. In this sense, future sales play the role of guarantee of repayment. There is limited liability in that if the state of economy ends up being worse than expected, financial intermediaries will at least recover as much as they can: total actual sales. ${ }^{12}$

Formally, firms will face the following constraint:

$$
(1+r) B_{t} \leq\left(1-\tau_{t}\right)\left[P_{t}(1+r) R_{t}+q_{t+1} P_{t+1}^{e} R_{t}+\left(1-q_{t+1}\right) P_{t+1}^{e}(1-d) R_{t}\right]
$$

where $r$ is the exogenous international real interest rate, $B_{t}$ represents the debt level in period $t$, $q_{t+1}$ is the probability that individuals attach to the state of nature being good in period $t+1$ as of period $t, P_{t}$ stands for prices in period $t$ and $P_{t+1}^{e}$ represents the expected price for period $t+1$ as of period $t . \tau_{t}$ is a tax rate that will be relevant in later. for the moment, assume $\tau_{t}=0 \forall t$. From (4) we can observe the maximum level of indebtedness that each firm will be allowed to by the financial sector:

$$
B_{t} \leq\left(1-\tau_{t}\right)\left[P_{t} R_{t}+\frac{q_{t+1} P_{t+1}^{e} R_{t}+\left(1-q_{t+1}\right) P_{t+1}^{e}(1-d) R_{t}}{1+r}\right]
$$

Intuitively, the financial sector will make loans to investor in such a way that the expected present discounted value of sales is greater than or equal to total indebtedness, i.e. that in expected value, repayment is guaranteed. Then, given that financial intermediaries are risk neutral they will be indifferent to make the loan when (4) becomes binding, determining the maximum debt that investors are ex ante able to take. Alternatively, $B_{t}$ can be interpreted as the present discounted value of debt to be repaid tomorrow.

Optimizing risk neutral agents will ex ante decide wether to invest or not, given available information, according to a net present value rule: invest whenever the expected present discounted value of investing today is greater than or equal to the expected - as of today - present discounted value of waiting for one period and then investing. This can be expressed as ${ }^{13}$

$$
N P V_{t}^{t} \geq N P V_{t+1}^{t}
$$

Where the superscript accounts for the moment in which the $N P V$ is computed and the subscript relates to the moment in which investment is actually made. In other words, given that delay gives the profit of enabling firms not to make mistakes - in the sense of investing and then observing that the state of demand is not as good as expected -, the payoff from not waiting has to be large enough to offset the benefits of waiting.

The expected net present value of investing today is the sum of the revenue due to current sales plus the expected discounted value of revenue obtained next period, where the latter can either increase or decrease depending on the state of nature, minus the present value of debt that investors

\footnotetext{
${ }^{12}$ We are abstracting from moral hazard-type of actions.

${ }^{13}$ As Bernanke (1983) and Dixit and Pindyck (1994) show this rule of thumb is derived from an optimization process.
} 
have to repay in case of asking for the necessary loan to finance their project. Since investors do not know ex ante what the true state of demand will be played by nature tomorrow, they have to compute expected values according to the probability they attach to each of states occurring next period given their information. Formally:

$$
N P V_{t}^{t}=\left(1-\tau_{t}\right)\left[P_{t} R_{t}+\frac{q_{t+1} P_{t+1}^{e} R_{t}+\left(1-q_{t+1}\right) P_{t+1}^{e}(1-d) R_{t}}{1+r}-B_{t}\right]
$$

Where the first term accounts for todays revenue, the second term represents the expected revenue for tomorrow (properly discounted) and the last term shows the present value of debt (repayment) that firms have to get in order to invest. Rearranging ${ }^{14}$

$$
N P V_{t}^{t}=-B_{t}+\frac{\left(1-\tau_{t}\right) P_{t} R_{t}}{1+r}\left[2+r-d+q_{t+1}(u+d)\right]
$$

In case firms choose to wait for one period before making the decision about investment, as of today they will compute the discounted value of investing in case the state of demand turns out to be good, taking into account the fact that, once in period $t+1$, if the state of nature ends up being bad, they will not invest at all. Algebraically, this can be expressed as follows ${ }^{15}$

$N P V_{t+1}^{t}=\frac{1}{1+r}\left\{q_{t+1} \times \max \left[0,\left(1-\tau_{t}\right) P_{t}(1+u) R_{t}-B t\right]+\left(1-q_{t+1}\right) \times \max \left[0,\left(1-\tau_{t}\right) P_{t}(1-d) R_{t}-B_{t}\right]\right\}$

In words, the individual will compute, as of today, the discounted value of expected profits to be obtained tomorrow. These will be higher in the good state of nature, which happens with probability $q_{t+1}$, than in the bad state of nature. For simplicity, and without loss of generality, we will assume that

$$
\left(1-\tau_{t}\right) P_{t}(1+u) R_{t}-B_{t}>0>\left(1-\tau_{t}\right) P_{t}(1-d) R_{t}-B_{t}
$$

so that projects are chosen only when profitable, i.e. when demand turns out to be high. Therefore this expression is reduced to

$$
N P V_{t+1}^{t}=\frac{q_{t+1}}{1+r}\left[\left(1-\tau_{t}\right) P_{t}(1+u) R_{t}-B_{t}\right]
$$

Consequently, rational risk neutral individuals will only invest in the current period if and only if (6) holds, where the expected net present values are given by expressions (8) and (11) respectively, i.e.:

\footnotetext{
${ }^{14}$ Observe that we are considering that $P_{t+1}^{e}=P_{t}$, but this is straightforward after one realizes that expected demand, $R_{t+1}^{e}=q(1+u) R_{t}+(1-q)(1-d) R_{t}$ is accounting for the probability of each state of nature happening and prices will endogenously be found. In a sense, in expected terms, price will remain constant given the Markov process structure.

${ }^{15}$ See Dixit and Pindyk (1994).
} 


$$
-B_{t}+\frac{\left(1-\tau_{t}\right) P_{t} R_{t}}{1+r}\left[2+r-d+q_{t+1}(u+d)\right] \geq \frac{q_{t+1}}{1+r}\left[\left(1-\tau_{t}\right) P_{t}(1+u) R_{t}-B_{t}\right]
$$

Rearranging we obtain the following key equation

$$
q_{t+1} \geq \frac{(1+r) B_{t}-\left(1-\tau_{t}\right) P_{t} R_{t}(2+r-d)}{B_{t}-(1-d) P_{t} R_{t}}=\bar{q}
$$

We observe that the probability of the state of nature being good has to be high enough for risk neutral investors to prefer investing today instead of waiting for more information. For them to be confident enough about their future ability to obtain profits, their own computed probability of the state of nature being good has to be sufficiently high. This condition implies that an entrepreneur will be happy to invest whenever $q_{t+1}$ is higher that some cut-off value given by the right hand side of (13). Lets call it $\bar{q}$. This is then simplified to investing today iff $q_{t+1} \geq \bar{q}$. Note also that $\bar{q}$ depends on the real interest rate and on the amount by which demand is decreased in case of the state of nature being bad. However, it is interesting to observe that it does not depend at all on $u$, the amount by which demand increases in case of the state of nature being good. ${ }^{16}$ When deciding whether to invest or not, there is no impact on the decision if the state of nature ends up being better than expected - if investment is irreversible - because the capital is already allocated for that purpose, so thats no extra information when deciding about investment. On the contrary, if the state of nature turns out to be worst than expected, that is a very relevant piece of information given that investment is irreversible. Specifically, an individuals decision to make irreversible investment will be affected, ex ante by the effects of bad news - should he knew -, but it should not be impacted by the potential effects of the economy being even better that expected. In a sense, the bad news principle can make delay the optimal policy. Then, only for very high expectations regarding the good state of nature will the entrepreneur choose to invest today instead of delaying.

Also, notice that given (4), a firm will ex post not be able to repay its debt - i.e. declare its bankruptcy - if in the bad state of nature

$$
(1+r) B_{t}>\left(1-\tau_{t}\right) P_{t} R_{t}+P_{t}(1-d) R_{t}
$$

which implies

$$
R_{t}<\frac{(1+r) B_{t}}{\left(1-\tau_{t}\right) P_{t}(2-d)}
$$

That is to say that for very low ex post prices - specifically, lower than expected given the economy's structure - it is likely for many firms that decided to invest not to be able of repaying their debts. Formally, ex post prices are the ones obtained after the market clearing condition is considered, namely

\footnotetext{
${ }^{16}$ See Dixit and Pindyck (1994), which resembles what Bernanke (1983) called the "Bad News Principle, as already noted above.
} 


$$
P_{t+1} \int_{0}^{1} a_{t}^{i} d i= \begin{cases}P_{t+1}(1+u) R_{t} & \text { if } S_{t+1}=G \\ P_{t+1}(1-d) R_{t} & \text { if } S_{t+1}=B\end{cases}
$$

Note that the lower the demand schedule is in period $t$, the lower $P_{t}$ will be and so the more likely for bankrupt firms to arise, so the recession might be become worse. In one sense, the lower the demand schedule is, the lower prices are, so the lower firms net worth will be - for both, the ones that invested in period $t$ and those that decided to wait for more information - so the ability of indebted firms to repay debts is dramatically hurt. Therefore, this will tend to make the recession to last longer, so a sort of vicious circle arises. Also, note that the repayment ability depends solely on $\mathrm{d}$ but not on $\mathrm{u}$, similar to the shown bad news principle, only that we are now looking at debts repayment instead of investment decisions.

\subsection{Computing $q_{t+1}$}

Up to now nothing has been said about how $q_{t+1}$ is obtained. We only know that once computed, each investor will compare it with $q$ in order to make his decision. However, we have assumed this is a model of incomplete information, so we have to be more specific about the informational structure of the economy.

Since there is a continuum of individuals of mass one, lets assume each one receives a private signal of the true state of nature. Naturally, with complete information, by just looking at how many individuals got the good state of nature signal, it is straightforward for agents to realize which is the actual state of nature and then make the decision. ${ }^{17}$ But usually, individuals have no access to the signals received by other agents. At most, they are able to observe their actions and draw conclusions out of them. Agents receive idiosyncratic signals which are private information. Looking at what others did and the signals privately obtained, firms infer whether they were right or not in the previous period. Given uncertainty, the best an individual can do is to conclude from others actions how wrong or right he was in assessing the future, weigh the information by its predictive power and re-compute it for the future. In this rational expectations context the learning process comes from a bayesian inference technology. Agents have priors about the probability of the state of nature being good and decide to invest according to them. After one period, each individual can learn from others actions (invest or not invest) in order to assess how right or wrong he was about the probability he estimated for the state of nature being good. Rationality implies updating the priors once new information is obtained, re-computing the estimated probability again, and so on and so forth, consistent with a dynamic framework.

To be more precise, recall that investors decide on their actions based on their estimated probability of the state of nature being good, namely $q_{t+1}$. Every period, rational agents will experience this type of updating based on information gathering. Using Bayes rule, each individual $i$ will

\footnotetext{
${ }^{17}$ Alternatively, this is the same as noting that for $\operatorname{Pr}\left[\xi_{t+1}=G \mid s_{t}=G\right]=m$ and $\operatorname{Pr}\left[\xi_{t+1}=B \mid s_{t}=G\right]=n, m>n$ implies that the economy is in the good state of nature.
} 
estimate the probability of next periods state of nature being good according to

$$
q_{t+1}^{i}\left(\xi_{t+1}^{i}, b_{t}\right)=\operatorname{Pr}\left[s_{t+1}=G \mid s_{t}=G\right] \beta_{t+1}^{i}+\operatorname{Pr}\left[s_{t+1}=G \mid s_{t}=B\right]\left(1-\beta_{t+1}^{i}\right)
$$

where

$$
\beta_{t+1}^{i}=\frac{b_{t}}{b_{t}+\left(1-b_{t}\right) \frac{\operatorname{Pr}\left[s_{t+1}=B \mid s_{t}=G ; \xi_{t+1}^{i}\right]}{\operatorname{Pr}\left[s_{t+1}=G \mid s_{t}=G ; \xi_{t+1}^{i}\right]}}
$$

and

$$
\frac{\operatorname{Pr}\left[s_{t+1}=B \mid s_{t}=G ; \xi_{t+1}^{i}\right]}{\operatorname{Pr}\left[s_{t+1}=G \mid s_{t}=G ; \xi_{t+1}^{i}\right]}=\frac{1-p}{p} \frac{w}{1-w}
$$

and $w=\operatorname{Pr}\left[\xi_{t+1}^{i}\right]=G, w>(1-w)$.

So the estimated probability of the state of nature being good for agent $i, q_{t+1}^{i}$, is equal to the probability of the state of nature being good given that it was good in the previous period times the privately updated probability of the state of nature being good (without considering the probability of switching due to the Markov process), $\beta_{t+1}^{i}$, plus the probability of the state of nature being good given that it was not good in the previous period times the privately updated probability of the state of nature not being good. The privately updated probability of the state of nature being good (without considering switching) is computed, using Bayes rule, based on public information from the previous period, $b_{t}$ - computed below - and the estimated likelihood of the state of nature changing given the private signal received by each agent $\xi_{t+1}^{i}$. The likelihood of state of nature changing is computed considering the probability of each state of nature happening given by the Markov transition matrix and the unconditional probability each agent has of receiving a signal that the state of nature is good, $w$. Without loss of generality, we assume that the probability of receiving a good signal is higher than the probability of receiving a bad signal, consistently on computing $q_{t+1}^{i}$ as the privately estimated probability of the state of nature being good based on both private and public information.

Therefore, in order for each agent to decide whether to invest now or to wait one period for more information, he has to previously asses the probability of the state of nature being good given private and public information. The next step is to determine how the public information is obtained. Firstly, lets denote total investment in period $t$ by $I_{t}$, such that

$$
I_{t}=\int_{0}^{1} a_{t}^{i} d i
$$

Suppose there is a public agency that is in charge of computing official statistics for the government. This office will be responsible for computing total investment each period once it surveys (observes) how many firms actually ended investing in each period. Also, this agency will compute at the beginning of period $t$ the probability of the of $I_{t+1}=1$, in period $t$ given the information the agency has available, which will be computed as 


$$
\begin{aligned}
& \operatorname{Pr}\left[I_{t+1} \mid b_{t}, s_{t}\right]=\int_{0}^{1} \operatorname{Pr}\left[q_{t+1}^{i} \geq \bar{q} \mid b_{t}, s_{t}\right] d i \\
& =\int_{0}^{1} \operatorname{Pr}\left[p \beta_{t+1}^{i}+(1-p)\left(1-\beta_{t+1}^{i}\right) \mid b_{t}, s_{t}\right] d i \\
& =\int_{0}^{1} \operatorname{Pr}\left[\beta_{t+1}^{i} \geq \frac{\bar{q}+p-1}{2 p-1} \mid b_{t}, s_{t}\right] d i \\
& =\int_{0}^{1} \operatorname{Pr}\left[\beta_{t+1}^{i} \frac{b_{t}}{b_{t}+\left(1-b_{t}\right) \frac{\operatorname{Pr}\left[s_{t+1}=B \mid s_{t}=G ; \xi_{t+1}^{i}\right]}{\operatorname{Pr}\left[s_{t+1}=G \mid s_{t}=G ; \xi_{t+1}^{i}\right]}} \geq \frac{\bar{q}+p-1}{2 p-1} \mid b_{t}, s_{t}\right] d i
\end{aligned}
$$

Then, using the same logic as before the agency can compute

$$
\eta_{t+1}\left(I_{t+1}, b_{t}\right)=\frac{b_{t}}{b_{t}+(1-b t) \frac{\operatorname{Pr}\left[I_{t+1}=1 \mid b_{t}, s_{t}=B\right]}{\operatorname{Pr}\left[I_{t+1}=1 \mid b_{t}, s_{t}=G\right]}}
$$

Finally, considering the Markov chain, the statistics office will be able to compute

$$
b_{t+1}=p \eta_{t+1}+(1-p)\left(1-\eta_{t+1}\right)
$$

The statistical agency, given available information will compute the probability of the state of demand being good at the beginning of period $t$. In order to do so, the agency does not have the idiosyncratic information that each individual receives. Therefore, they will first compute the probability of aggregate demand for investment being equal to one, that is the probability that every individual decides to invest - meaning that everyone thinks the good state of nature will occur - given their public information. This is done based on the estimated official probability, $b_{t}$, computed at the beginning of period $t$ and the state of nature observed by the agency at the end of the current period -i.e. after investment decisions have been made. But since this agency does not actually knows the aggregate economys investment in advance, it will also have to estimate the probability of the state of nature being good and aggregate accordingly taking the previous periods computed probability for the state of nature being good and considering the likelihood of high aggregate demand (everyone investing) given the previous periods computed $b$ and the state of nature spectrum. Then, taking into account the probability of switching given by the Markov process, the agency computes this periods probability of the state of nature being good. Agents making their decision investments in period $t+1$ will use this latter probability in order to asses the privately estimated probability of the state of nature being good given their information. Consequently, the information cycle keeps on going.

In summary, individuals have to make irreversible investment decisions with incomplete information. This implies that they will first have to assess the probability of the state of nature 
being good and then to choose their optimal actions. The information structure of the economy we described is as follows. Agents have public information regarding the actions that everybody decided to take in the previous period; they also have information of previous periods aggregate demand. In addition, they receive idiosyncratic signals regarding the state of nature and they also receive public information corresponding to the previous periods actions of the aggregate economy. Moreover, they also get information, computed by the statistical agency, regarding their estimated probability of the state of aggregate demand being high. Using all this information they privately compute the probability of the state of nature being good and compare it to a cut-off value given by fundamentals. From the latter comparison they make the decision of whether to invest or to wait for more information. After investment decisions are made, the statistical agency computes aggregate investment and estimates the probability of the state of nature being good for the next period, which is made public for next periods investment decisions. Then is straightforward to note that the informational cycle continues as well as investment decisions. Given the irreversible nature on investment, the economy ends up displaying asymmetric business cycles with abrupt slumps and slow recoveries.

In this case, an example should help in clearing things up. Suppose the economy is currently producing at full capacity so that for each firm $q_{t+1} \geq \bar{q}$. Now assume that the following period the state of nature turns out to be bad. This will cause many firms to compute a $q_{t+1}$ below the cut-off value, i.e. not to invest, so that production decreases. Notice that for a similar positive shock the production pattern will not change because it was already giving a qt+1 above the threshold. Therefore we observe an asymmetry in terms of the impact that a shock of the same size can have on the investment decisions of optimizing agents. This non-linearity stems from the decision rule that entrepreneurs use to make their decisions. Moreover, even if in the following period the good state of demand appears, given that investors not only consider the piece of private information they receive, but also the upward or downward revision of the public information - which in this example was revised downwards due to investment ending up being less than expected - the new $q_{t+1}$ will increase but not as a much as if there were complete information. This implies that even in the good state of nature many entrepreneurs that would have otherwise invested will currently not due to the uncertainty about the likelihood of the state of demand being good. Given that this means than investors will practice the wait and see strategy, the $q$ will take more time to recover and so will investment and output. In this sense, there is also an observed asymmetry in terms of quick slowdowns and slow recoveries.

Observe that the model also predicts asymmetry in terms of impact. If the economy is hit above the cut-off $q$, the logic regarding the asymmetry on impact is the one stated above. But also, if the economy is affected when the $q_{t+1}$ is below the threshold the same negative shock depressed the $q$ more than the positive one, making the recession to recover even slower! This might become clearer by inspection of Figure (???).

INSERT FIGURE II HERE

It can be seen in the picture that if the economy starts below the threshold $A$ the impact is not 
the same due to the effect that public information revision plays in computing the likelihood of the state of nature being good. However, this is precisely the point to make, in that negative shocks affect the economy more than positive ones, regardless of the state of nature where we start from. This unconditionality in the asymmetry is consistent with Veldkamp (2001).

Note further that the higher the degree of private information in the economy, the slower the economy recovers from negative shocks ${ }^{18}$ due to the lack of public information. As already noted, without private information all the discrepancies in investment decisions will disappear, implying that cycles will describe only technological fluctuations as in the standard RBC model.

\section{Adding the Government}

\subsection{Some Identities}

Suppose a non-monetary economy in which we add the existence of an infinitely lived government. Each period, the government can finance its expenditure by two means: tax revenue and debt issuance (similar to obtaining loans). We assume that governments debt is only internationally traded. We also assume that public debt has a one period maturity. Consequently each period the government will get the funds for its purchases not obtained from taxes by issuing debt so as to cover the total budget deficit. The latter will include primary deficit plus interest payments. Tax collection only comes from firms sales. Therefore the governments flow budget constraint will be given by

$$
P_{t} \tau_{t} R_{t}+D_{t}=g_{t}+(1+r) D t-1
$$

where $\tau_{t}$ represents the tax rate on sales in period $t, g_{t}$ stands for governments expenditures during period $t$ and $D_{t}$ is the debt level acquired at the end of period $t$.

As above stated, the effect of a recession on the fiscal authority is to reduce tax collection. Due to the market forces that generate many firms not being able to repay their debts and consequently become bankrupt, it is straightforward to see that these firms will not continue paying their taxes since they get out of the market. Then fiscal revenue directly decreases in case a recession ends up being deeper or longer than expected; this is also worsen by the fact that a longer or deeper than expected recession makes more firms to optimally choose delay as their action, so the problem is reinforced. Consequently, the government will be faced, for given taxes, with two basic alternatives, either decrease government expenditures or increase debt levels more than expected. ${ }^{19}$ This is because the government must show, the same as private firms, expected intertemporal sustainability. All else equal, lower tax revenue call for adjusting the fiscal budget constraint somehow.

Clearly, the optimal policy for a government realizing of a deeper than expected recession, in order to keep on showing intertemporal solvency, is to decrease government expenditures, for

\footnotetext{
${ }^{18}$ Exogenous shocks can be simply modelled as exogenous changes in aggregate investment levels.

${ }^{19}$ We are obviously abstracting from any possible ex post repudiation strategy on the governments side.
} 
otherwise the market will internalize the inability of the fiscal authority to repay its debt in the very short run. Again, it is important to stress that we are referring to expected intertemporal solvency. If after one period the economy turns out to be better than expected then the government will be able to increase government expenditures. However, if this is not the case, if the government does not reduce its purchases, then more debt will have to be issued to finance the deficit.

Note that the higher the amount of outstanding debt, the higher the amount of interests due each period. For an economy that continues in recession and for which government expenditures are not reduced, then debt will be growing at an increasing rate. But yet intertemporal solvency cannot be forgotten. Given this, the fiscal authority will not be able to continue with this process for long periods, especially if the initial debt level was - although previously sustainable - already too high. Then, the economy can perfectly reach the maximum debt level tolerated by the market. ${ }^{20}$ International capital markets will not finance any extra dollar of public expenditures whenever the governments indebtedness attains that value. Then, if the economy has not gotten out of recession or the government does not adjust its expenditure level, eventually no roll over will be given to the country. Moreover, the deeper or longer the recession is, the higher the amount of new debt that the government has to raise each period. But since the higher the debt level, the higher interest payments are,${ }^{21}$ this implies the maximum accepted debt level will be reached earlier. This naturally calls for decreasing government expenditures directly and not to increase national debt worthlessly. ${ }^{22}$

Formally, we can show the above mentioned statement by just playing around with the budget constraint. Let $D_{T}^{\max }$ be the maximum debt level a country can re-finance, which will be attained in period $T>t$. We can compute its present value as

$$
\frac{D_{t}^{\max }}{(1+r)^{T-t}}
$$

Then

$$
\sum_{s=t}^{s=T}=\frac{g_{s}-P_{s} \tau_{s} R_{s}}{(1+r)^{s-t}}=\frac{D_{t}^{\max }}{(1+r)^{T-t}}
$$

Consequently, intuition is supported by (26). For a given tax rate and given government expenditures, the deeper the recession is, the lower tax collection results. For a given maximum attainable debt level, this implies that $T$ is reduced, in the sense that the moment in which the government can no longer engage in rolling over its debt comes earlier. ${ }^{23}$

By introducing uncertainty, the same result holds. Since the government has to be ex ante

\footnotetext{
${ }^{20}$ This is parallel to introducing a No Ponzi Game condition for intertemporal solvency.

${ }^{21}$ Note that is exacerbated if we consider a risk premium that increases with debt, which will be done below.

${ }^{22}$ Governments increase in public expenditures as a coordination device to boost the economy out of recession only proves to work for low indebted countries (mainly developed countries), as will be shown below.

${ }^{23}$ Once more, note we are still abstracting from risk premium effects which make debt to grow with the debt level, as in Magud (2002).
} 
solvent, its flow budget constraint turns to

$$
\tau_{t}\left[q_{t+1}^{G} P_{t}(1+r) R_{t}+\left(1+q_{t+1}^{G}\right) P_{t}(1-d) R_{t}\right] \geq-D_{t}+(1+r) D_{t-1}+g_{t}
$$

and in parallel to our previous analysis, $q_{t+1}^{G}$ accounts for the probability of the state of nature being good attached by the public sector. However, ex post, in the bad state of nature, this flow constraint will become

$$
\tau_{t} P_{t}(1-d) R_{t} \geq-D_{t}+(1+r) D_{t-1}+g_{t}
$$

But if $P_{t}$ turns out ex post to be even less than expected, then from (28) we can see that for a given $g_{t}$ the roll over ability of the government decreases and so the mentioned effect arises. The lower the ability of a government to roll over its debt, the lower the price of its bonds, since no investor wants to have them in his investment portfolio. Consequently, the risk premium has to increase, which will be reflected in a higher interest rate on government bonds or loans made to the government. ${ }^{24}$ Then we see that the governments ability to rolling over is further spoiled.

This emerges as a direct consequence of including the market clearing conditions for this expanded version of the model. Ex post market clearing in very period is defined by

$$
P_{t+1} \int_{0}^{1} a_{t}^{i} d i= \begin{cases}P_{t+1}(1+u) R_{t}+P_{t+1} g_{t} & \text { if } S_{t+1}=G \\ P_{t+1}(1-d) R_{t} & \text { if } S_{t+1}=B\end{cases}
$$

This condition implicitly defines the ex post endogenous price level of the economy. Note that, if aggregate demand ends up being less than expected by entrepreneurs when they made their investment decisions, the market clearing price will be lower than expected, causing the above mentioned -Fishers type- mechanism to be generated. In this sense, the hypothesized result is a naturally plausible outcome of the economy.

The conclusion that we can draw out of this is that although public investment might work to coordinate agents in solving the coordination failure due to incomplete information, it will only actually be efficient when dealing with a low indebted country, or one which enjoys a very high intertemporal solvency, as shown below.

\subsection{Counter-Cyclical Fiscal Policies, its Effectiveness and the Relevance of Ini- tial Conditions}

As we put it by now more than once, the effectiveness of counter-cyclical fiscal polices as a coordination device might not always prove useful. In fact, we said, depending on the initial condition that describes the economys structure, the first best policy reaction is likely to substantially change. Furthermore, if we look at a developed country with high credibility or simply to a country that enters into recession with a relatively low debt level, using expansionary fiscal polices 'a la Keynes

\footnotetext{
${ }^{24}$ For a detailed analysis of endogenous risk premium and unexpected changes in real prices see Magud (2002).
} 
will work as a mechanism to get the economy out of the recession. However, when dealing with a country suffering credibility problems, which can be the reflection of high indebtedness level, these counter-cyclical actions will show no positive effect. Moreover, the recession could be made even worse.

The idea is trying to represent the degree either of development or of credibility by as fewer variables as possible. For the sake of simplicity, lets represent this by the level of debt a country has at the moment that the recession starts.25 It will shown that for relatively small levels on initial indebtedness expansionary fiscal polices can make the economy escape from recession whereas the opposite effect will be observed for highly indebted countries.

By considering the government as another -special- participant in the above stated model, equations (4), (5), (7), (8), (9), (10), (11), (12), (13), (14), and (15), now have $\tau_{t} \geq 0 \forall t$. All other equations remain the same. Additionally, the government can also invest, which will be reflected as an increase in government expenditures without specifically making the distinction within the public accounts. It is worth pointing out that private investors being infinitesimally small do not internalize the amount of goods and services purchased by the government when making their investment decisions. Formally, for the individual firm we observe that $E_{t}\left[g_{t+1} \mid q_{t+1}\right]=0$. This then implies, as above, that given available information $E_{t}\left[P_{t+1} \mid q_{t+1}\right]=P_{t}$.

Now, lets consider the effects of the following policy experiment: increasing government expenditures when the demand ends up being less than expected. To restate the problem, suppose the government realizes that the recession is longer or deeper than expected and consequently decides to intervene in the market by increasing its spending.

In this case, the flow budget constraint to consider is the one given by (28), but now the international lending sector will solve for the real interest rate to charge to both the private as well as the public sector out of the interest rate charged to the government. ${ }^{25}$ Inspection of (28) reveals that, ceteris paribus, the interest rate will increase with increases in government expenditures.

Therefore, we now have an endogenous interest rate. Then, if as the proposed exercise suggests, the government increases its expenditures more than expected for $t+1$, the real interest rate will be driven up for the whole economy. The increase in the cost of credit impacts on investment by affecting the cut-off level for $q$ (observe (13)), thus reducing investment, i.e., making the incentives for production to be reduced.

On the other hand, notice that increasing government expenditures implies demand going up, so this generates positive incentives for firms to be happy to produce. Depending on which of the two effects dominates, so will be the expansionary or contractionary effects of increasing public spending.

Note incidentally from (26) and (28) that the higher the debt level at the moment of unexpectedly increasing government expenditures, the lower the margin for the public sector to generate a sharp increase in demand; therefore, the higher the debt, the less likely for the expansionary effects of fiscal policy to arise.

\footnotetext{
${ }^{25}$ We are thus assuming that the international interest rate faced by private agents is attached to the country
} 
In the appendix it is shown than

$$
\frac{\Delta \bar{q}}{\Delta g_{t}}= \begin{cases}<0 & \text { for relatively large increases in government expenditures } \\ >0 & \text { for relatively large decreases in government expenditures } \\ <0 & \text { for relatively small decreases in government expenditures } \\ >0 & \text { for relatively small increases in government expenditures }\end{cases}
$$

Which implies that the effect of government expenditures on the threshold is a priori ambiguous. Depending on which effect dominates, i.e. if government expenditures affects more the price through market clearing conditions - or the interest rate, so will be determined if changes in government expenditure will be contractionary of expansionary.

Then we can say that large government expenditures increases are needed to generate expansionary fiscal policies 'a la Keynes, but that mild expansions will end up being contractionary. Furthermore, for high debt levels, given that large expansions in public spending are not possible without modifying taxes, fiscal contractions can be expansionary provided they come as sharp cuts in government purchases. This can be appreciated in the latter expression, where only high changes in government expenditures -either expansions or contractions- end up being expansionary in terms of output. In the case of an increase in public spending, it has to large enough so that its effect on aggregate demand compensates for the lower incentives to produce in the private sector. Regarding the fiscal contraction, it also has to sufficiently sharp so as to incentive private production despite its effects on prices.

Clearly, for government expenditure to be large, the higher the capability the government has to have to issue more debt. If the countrys public debt is near to the maximum permitted by intertemporal solvency (26), then the ability of the government to react to the problem by expansionary fiscal policy is curtailed. On the contrary if there is enough room for new debt issuing -something likely if the economys indebtedness is far away the maximum - then counter-cyclical fiscal policy will prove effective.

Then, which countries are more likely to have enough degrees of freedom so as to use this type of policies? It is straightforward to notice that developing countries can only use this mechanism to offset recessions if they are operating at low debt levels. If not, reducing government expenditures and so showing public intertemporal solvency is the necessary action. For note that reducing gt will reduce the cut-off value generating better conditions for private investment. Investors, when facing the opportunity to invest will be more likely so to act.

Regarding developed countries, they can make use of each of the available polices, since usually solvency is not an issue for them. Credit markets will not generally be expecting developed countries to default on their debt, so funds accrue to them in case of need. Note also this applies when dealing with BOP crises generated by unexpected recessional effects because the same type of mechanism is put into motion.

Dealing with credibility has exactly the same implications because credibility implies existence 
of funds to finance hard times. Basically, developed countries are more credible in the sense that their ability to repay its debt is rarely put into question. So, since solvency for these countries does not wake up the ghost of default, they dont have to worry of whether expansionary fiscal policy will work or not; they only have to asses which is more effective. Note incidentally that in terms of long run sustainability, decreasing government expenditures might be the best candidate for a first best. This is due to intertemporal solvency, which must be always ex post fulfilled.

\section{Concluding Remarks}

What should a government do when faced with a recession? As shown above, the optimal policy will depend on initial conditions once the intertemporal solvency constraint is internalized. This implies that for highly indebted countries reducing government expenditures proves to be a better policy because of its expansionary effects in terms of output, whereas increasing government expenditures turns out to be contractionary. On the contrary, for developed countries the choice for the government to take the economy out of a recession is the standard keynesian recipe of increasing government expenditures. In this sense, one novel feature of this model is to consider the role of the government in the social learning literature as well as endogeneizing the optimal fiscal policy response. Moreover, as the evidence for some European countries show, using the former mechanism also works in boosting the economy out the low activity phase. ${ }^{26}$

Regarding the source of business fluctuations, the paper explores a new variant of why GDP dynamics display an asymmetric plot. Intuitively, given the uncertain nature of the future, investors might prefer to delay their investments for more information to accrue. As a consequence, even in periods where no recession should be observed if information were symmetric, due to this informational market failure, the economy will experience welfare reductions associated with the former that will result in the mentioned asymmetric pattern of economic fluctuations. Negative shocks will take more time to be accommodated than positive ones. ${ }^{27}$ Furthermore, the "on impact effect that positive shocks will generate is shown to be of smaller size than the negative shocks, contributing to another source of asymmetry.

In correspondence with both, the asymmetric characteristics of cyclical fluctuations and the role the government can play as a coordinating device - provided ex post sustainability is fulfilledthe fiscal authority can help the economy by means of welfare improving actions but taking into account that not always two countries should necessarily use the same type of counter-cyclical policy as the optimal instrument. Which policy response is to be considered sharply depends on the type of country under analysis.

\footnotetext{
${ }^{26}$ Moreover, there is some empirical evidence from Sweeden in Giavazzi and Pagano (1995) that shows the contractionary effects of fiscal expansions is also a possible outcome under some specific characteristics. Recent evidence of this topic can also be found in Hallet, Strauch and Von Hagen (2001) and in Barry and Devereux (2001).

${ }^{27}$ Magud (2002) explores a open economy variant of this model in which financial accelerator mechanisms display similar results for emerging markets and calls for the exchange rate regime to put into motion as a function of the degree of indebtedness of the economy and the tradable-nontradable ratio in the output structure of the economy.
} 


\section{References}

ACEMOGLU, D. and A. SCOTT (1997), "Asymmetric Business Cycles: Theory and Time-Series Evidence, Journal of Monetary Economics, 97, 40, 501-533.

ALESINA, A. and S. ARDAGNA (1998), "Tales of Fiscal Adjustments, Economic Policy, XXVII.

AlESINA, A., M. de BROECK, A. PRATTI and G. TABELLINI (1992), "Default Risk on Government Debt in OECD Countries, Economic Policy.

ALESINA, A. and R. PEROTTI (1997), "Fiscal Adjustments in OECD Countries: Composition and Macroeconomic Effects, IMF Staff Papers, June, XLIV, 210-248.

AlESinA, A., S. ARDAGNA, F. SCHIANTARELli and R. PEROTTI (1999), "Fiscal Policy, Profits and Investment mimeo, NBER Working Paper 7207, forthcoming in American Economic Review.

BALDACCI E., M. CANGIANO, S. MAHFOUZ and A. SCHIMMELPFENNIG (2001), "The Effectiveness of Fiscal Policy in Stimulating Economic Activity: An Empirical Investigation, IMF.

BARRY, F. and M. DEVEREUX (2001), "Expansionary Fiscal Contraction: A Theoretical Exploration, mimeo, University of British Columbia.

BEAUDRY, P. and G. KOOP (1993), "Do Recessions Permanently Change Output?, Journal of Monetary Economics, 31, 149-163.

BERNANKE, B. (1983), "Irreversibility, Uncertainty and Cyclical Investment, Quarterly Journal of Economics, 98, (1), 85-106.

BERNANKE, B. and M. GERTLER (1989), "Agency Costs, Net Worth, and Business Fluctuations, American Economic Review, 79, 14-31.

BERNANKE, B. and M. GERTLER (1990), "Financial Fragility and Economic Performance, Quarterly Journal of Economics, 105, 87-114.

BERNANKE, B. and M. GERTLER (1995), "Inside the Black Box: the Credit Channel of Monetary Policy Transmission, Journal of Economic Perspectives, 9, 27-48.

BERNANKE, B., M. GERTLER and S. GILCHRIST (1999), "The Financial Accelerator in a Quantitative Business Cycle Framework, in J. Taylor and M. Woodford, eds, Handbook of Macroeconomics, Elsevier, North Holland.

BLANCHARD, O. (1990), "Comment on Giavazzi and Pagano, in O. Blanchard and S. Fischer, eds, NBER Macroeconomics Annual, Cambridge, MA, MIT Press, 111-116. 
BLANCHARD, O. and R. PEROTTI (2000), "An Empirical Characterization of the Dynamic Effects of Changes in Government Spending and Taxes on Output", mimeo, MIT.

BERTOLLA G. and A. DDRAZEN (1993), "Trigger Points and Budget Cuts: Explaining the Effects of Fiscal Austerity, American Economic Review, March, 83 (1), 11-26.

BURNSIDE, C., M. EICHENBAUM and J. FISHER (2001), "Assessing the Effects of Fiscal Shocks, mimeo.

CAPLIN, A. and J. LEAHY (1994), "Business as Usual, Market Crashes, and Wisdom After the Fact, American Economic Review, June, 84 (3), 548-565.

CAPLIN, A. and J. LEAHY (1993), "Sectoral Shocks, Learning and Aggregate Fluctuations, Review of Economic Studies, 60, 777-794.

CHALKLEY, M. and I. H. LEE (1998), "Learning and Asymmetric Business Cycles, Review of Economic Dynamics, 1, 623-645.

CHAMLEY, C. (1997), "Social Learning, Delays, and Multiple Equilibria, EHESS, mimeo.

CHAMLEY, C. and D. GALE (1994), "Information Revelation and Strategic Delay in a Model of Investment, Econometrica, September, 62 (5), 1065-1085.

DIAMOND, P. (1981), "Aggregate Demand Management in Search Equilibrium, Journal of Political Economy, 90 (5), October, 881-894.

DIXIT, A. and R. PINDYCK (1994), "Investment under Uncertainty, Princeton University Press, New Jersey.

DRAZEN, A. (1990), "Comment on Giavazzi and Pagano, in O. Blanchard and S. Fischer, eds, NBER Macroeconomics Annual, Cambridge, MA, MIT Press, 117-122.

DRAZEN, A. (2000), "Political Economy in Macroeconomics, Princeton University Press, Princeton, New Jersey.

EDELBERG, W., M. EICHENBAUM and J. FISHER (1999), "Understanding the Effects of a Shock to Government Purchases, Review of Economic Dynamics, 166-206.

FISHER, I. (1933), "The Debt-Deflation Theory of Great Depressions, Econometrica, 1, 337357.

GALE, D. (1996a), "Delays and Cycles, Review of Economic Studies, 63 (2), 169-198.

GALE, D. (1996b), "What have we Learned from Social Learning, European Economic Review, 40, 617-628. 
GERSBACH, H. (1997), "Financial Intermediation, Capital Spillovers and Business Fluctuations, mimeo, Alfred-Weber Institut, University of Heidelberg.

GIAVAZZI, F. and M. PAGANO (1996), "Non-Keynesian Effects of Fiscal Policy Changes: International Evidence and the Swedish Experience, Swedish Economic Policy Review, III, Spring, $67-112$.

GIAVAZZI, F. and M. PAGANO (1990), "Can Severe Fiscal Adjustments be Expansionary?, in O. Blanchard and S. Fischer, eds, NBER Macroeconomics Annual, Cambridge, MA, MIT Press, 75-110.

HALLET, A., R. STRAUCH and J. Von HAGEN (2001), "Budgetary Consolidation in Europe: Quality, Economic Conditions and Persistence, mimeo.

KEYNES, J. M. (1936), "The General Theory of Employment, Interest and Money, Macmillan, London.

KIYOTAKI, N. and J. MOORE (1997), "Credit Cycles, Journal of Political Economy, 105, 211-248.

MAGUD, N. (2002), "Liability Dollarization, Openness and Exchange Rate Regime, mimeo, University of Maryland.

MILLER, M., R. SKIDELSKY and P. WELLER (1990), "Fear of Deficit Financing - Is it Rational?, in R. Dornbusch and M. Draghi, eds, Public Debt Management: Theory and History, Cambridge University Press, Great Britain.

MITCHEL, W. (1927), "Business Cycles: the Problem and its Setting, NBER, New York.

NEFTCI, S. (1984), "Are Economic Time Series Asymmetric over the Business Cycle?, Journal of Political Economy, 92 (2), 307-328.

PEROTTI, R. (1998), "Fiscal Policy in Goods Times and Bad, mimeo, University of Columbia.

TALVI, E. and C. VEGH (2000), "Tax Base Variability and Procyclical Fiscal Policy, NBER Working Paper 7499.

SICHEL, D. (1989), "Are Business Cycles Asymmetric? A Correction, Journal of Political Economy, 97 (5), 1255-1260.

STOCK, J. and M. WATSON (2000), "Business Cycles Fluctuations in US Macroeconomic Time Series, in J. Taylor and M. Woodford, eds, Handbook of Macroeconomics, Elsevier, North Holland.

SUTHERLAND, A. (1997), "Fiscal Crises and Aggregate Demand: Can High Public Debt Reverse the Effects of Fiscal Policy?, Journal of Public Economics, 65, 147-162. 
VELDKAMP, L. (2001), "Slow Boom, Sudden Crash, INSEAD, forthcoming in American Economic Review.

ZEIRA, J. (1994), "Informational Cycles, Review of Economic Studies, 61, 31-44.

ZEIRA, J. (1999), "Informational Overshooting, Booms and Crashes, Journal of Monetary Economics, 43, 237-257.

\section{A Appendix}

The objective of this appendix is to show the effects of government expenditure on the cut-off value for the investment decisions, $q$. Differentiate (13)) with respect to $g_{t}$, to obtain

$$
\frac{\partial \bar{q}}{\partial g_{t}}=\frac{\left[B t-(1-\tau) P_{t} R_{t}\right] \Omega \frac{\partial r}{\partial g_{t}}+\left[(1-d)(1-\tau) R_{t} \Gamma-(1-\tau) R_{t}(2+r-d) \Omega\right] \frac{\partial P_{t}}{\partial g_{t}}}{\Omega^{2}}
$$

where

$$
\Gamma=(1+r) B_{t}-(1-\tau) P_{t} R_{t}(2+r-d)
$$

and

$$
\Omega=B_{t}-(1-d)(1-\tau) P_{t} R_{t}
$$

It is straightforward to notice that $\frac{\partial r}{\partial g}>0$ and that $\frac{\partial P}{\partial g}>0$. Also, by inspection of (10), we can see that $\Omega>0$. Then, note that we can rewrite $\Gamma=\Omega(1-\tau)(1-d) P_{t} R_{t}$. For an interior solution to exist - i.e. $\bar{q} \in[0,1]$ we need to observe $\Gamma>0$.

Afterwards, by focusing on the first term in (A.1), the sign of $\left[B t-(1-\tau) P_{t} R_{t}\right] \Omega$ - is then obtained by looking at the first factor. Note that by $\left(\right.$ A.2) $\Gamma=(1+r)\left[B_{t}-(1-\tau) P_{t} R_{t}-\frac{(1-\tau)(1-d) P_{t} R_{t}}{1+r}\right] \geq$ 0 which necessarily implies

$$
B_{t}-(1-\tau) P_{t} R_{t}>0
$$

The final step is to look at the second term. Notice that after some manipulations we can observe that

$$
(1-d)(1-\tau) R_{t} \Gamma-(1-\tau) R_{t}(2+r-d) \Omega=(1-\tau) R_{t}[(1-d)(\Gamma-\Omega)-(1+r) \Omega]<0
$$

due to $\Gamma \leq \Omega$.

As a consequence, we can notice that 


$$
\operatorname{sign}\left[\frac{\partial \bar{q}}{\partial g}\right]=\operatorname{sign}\left[\frac{(+)(+)+(-)(+)}{(+)}\right]
$$

Therefore the sign of the effect of public expenditures on the cut-off value for investment decisions is ambiguous. For large increases in government expenditures the expression will be negative, thus reducing the cut-off $\bar{q}$ and consequently boosting investment, whereas for small increases it will positive and the opposite will be true. Similarly, for small reductions in government expenditures, the cut-off increases, thus reducing output, unlike when the expenditures contraction is sufficiently large. 